\title{
Staying Competitive in Today's Manufacturing Environment and World Wide Off- Shore Sourcing
}

\author{
C. Harding \\ Manufacturing Resource Group, Linamar Corporation, Guelph, Ontario \\ colin.harding@linamar.com
}

\begin{abstract}
In order to be competitive in today's world marketplace, companies must replace the trial and error methods of product development of yesterday with lean efficient methods. This encompasses all stages from concept through design and development, to manufacturing and delivery to the final customer. We must ensure designers are creating their products based on a solid appreciation of materials and forming methods, manufacturing and assembly, costs and lessons learned. In this paper examples are drawn from automotive and aerospace industries.
\end{abstract}

\section{Introduction}

Over time engineers have gone from having a broad education with a wide range of experience in many related areas, to today's specialization. This has resulted in teams of specialists creating products and excessive time being spent in communication between team members. There is an inherent lack of efficiency in this process since the designer is constantly needed to interact with the team in order to keep the process moving.

On a complex assembly, such as an automatic transmission, many teams are assigned responsibility for groups of parts. Usually, these groups are related, i.e. shafts, housings, clutches etc.

The teams may have to share specialized resources such as metallurgy, welding or bearings. This can give rise to time conflicts with the resources being required by more than one team at the same time. It is not uncommon for specialists to spend all day in meetings leaving little time for anything else. This can lead to timing delays.

Transmission projects also have teams at multiple levels whose responsibilities are the integration of each part or module into a coherent product that performs as required. This highlights the need for parts to work together within the assembly and their interdependence for space and performance. Therefore, a change in one part can cause changes in the multiple parts with which they interface.

How many times have we seen drawings issued for manufacturing only to have them returned with a list of requested changes?
These are all in the name of "manufacturability"? Sometimes these changes affect the way the raw material is produced, i.e. a change from a forging to a casting, a change in grade of material, a special process change from carburized to induction hardened for cost reduction, a request for re-dimensioning or simply the part just cannot be economically manufactured due to its configuration. Not to mention the bruised ego's that happen when design and manufacturing conflict.

Too many times it appears there is a fence dividing the two groups resulting in a loss of efficiency and an apparent lack of co-operation. It is easy to see the opportunities that exist for delays, cost increases and the possibility of a loss of performance in the finished product.

Each time we develop a new or improved product we can forget to learn from past experience. It is easier to copy past designs or dimensioning schemes than to gain a thorough understanding of the product and lessons learned. Too many times a new engineer is assigned to a part and left to learn by himself. Documentation may not be up to date, which leads to repeat mistakes.

Today's engineers entering the workforce or who are changing occupations may be well experienced in computers and software but may be totally lacking in the aspects of industry quality and manufacturing systems. The automotive standards are very detailed and their implementation can present difficulties to these engineers. Add to this the in-house procedures for design control and other procedures and a new engineer can be overwhelmed. 
We have all seen the trend in industry where companies have disappeared because they were uncompetitive both technically and economically. This paper aims to show reasons for this and ways to prevent such failure.

\section{Design systems and standards}

Every company has developed systems and standards that the product development and manufacturing departments must follow. Some of these standards, i.e. ISO 9000 and TS16949 [1], are recognized world wide with ISO-9000 being used in industry and non-manufacturing companies. ISO TS16949 is an automotive industry standard. Many Tier One suppliers and many lower tier companies work to TS16949. Many times this is a condition of being a supplier to the automotive industry. Certainly, if a supplier is not registered as TS16949 compliant, they will have procedures in place that cover the important requirements. Figure 1 shows TS16949 and Automotive Industry Action Group (AIAG) [2] manuals.

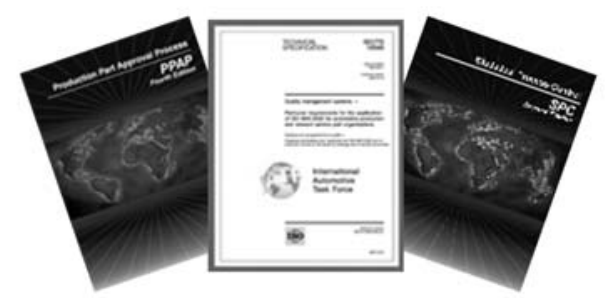

Figure 1. Quality System manuals

In these standards there are complete sections covering design and testing through manufacturing. In addition, many customers may have their own standards called "Customer Specific Requirements" that also need to be implemented by suppliers. These are very specific requirements, i.e. quality capability or test department requirements.

Companies also have developed methods for product engineers that ensure there are solid controls in place for: layout of drawings, CAD layer control, dimensioning, changes and revisions, approvals, how to issue drawings, confidentiality, file systems, drawing numbering and naming conventions and other support functions. These are rigidly followed.

The development of prototypes, from mules through pre-production and the testing of them on test stands or in vehicles, is controlled by procedures. An engineer working in this area needs to follow the procedures and pay attention to documentation of all stages and revisions or changes to parts or assemblies.
The effect of each change needs to be understood so the final product meets its performance requirements.

When 16 million vehicles are produced each year in North America and they all need servicing for the life of the vehicle model, plus another 7 years minimum, we can imagine the number of product improvements that happen. There is a need to track these changes through models and serial numbers so the service organization can identify the required part for any vehicle.

The idea that a design engineer spends all day at his CAD station, designing space shuttles, is not realistic. Graduate engineers must be prepared with a general knowledge of systems and standards in order to improve the time taken to be productive in their job and to understand the need for meticulous documentation.

\section{Lessons learned}

At design reviews, many have seen the "big book" be brought out as a reference. In this book are drawings of the part being reviewed that the customer has produced for the last 25 years. This will be the standard for the new part being designed. When asked why we are doing it the same way, no one can explain except that it is either "the way they do things" or they just know "it works". Over time the understanding of the design has been lost through transfers, promotions, quits, retirements, lack of training, poor documentation or other reasons. If documentation of the last 25 year's experience is in place and new engineers are trained by experienced, seasoned engineers, then the effect of manpower changes would not be so disruptive.

If a supplier asks for a design change that could lead to a significant cost reduction and the design engineer does not understand the part design, then how will he/she make a decision? This happens more often than we admit.

Let us not forget the huge amount of information and experience that accumulates in the dealer service departments and with warranty returns. The design engineer needs to be encouraged to go into the field to visit service departments and talk to customers for their experiences with the products. The same can be said for visits to the manufacturing site. They may be living with issues that make production of the part more expensive. Additionally, they may be having ongoing quality problems.

Any product, material or process can be improved. If we don't, then a competitor will take advantage of the situation. Consequently, we will start to loose market share. Through lessons learned we can 
continually make improvements that keep the product as the market leader.

\section{Design for manufacturing - Materials}

Many times the greatest cost driver is the cost of the raw material and the scrap generated through poor understanding of the benefits and disadvantages of the different processes. This covers mainly castings and forgings. Wrought products, i.e. bar stock, are not efficient in high volume production unless it is close to finished size. One exception is tubing which is very efficient for hollow cylindrical parts.

Forgings and castings are near net shape, can be of complex configuration and come in a wide range of materials including ferrous irons, steels, non ferrous aluminum, copper and other alloys. With such versatility, why do we have so many manufacturing disasters related to materials, especially castings? To answer this we need to look at some typical mistakes that product designers keep making.

Sand castings, shell castings, lost foam castings, semi-permanent, permanent and die castings are the main production casting methods used by industry. The main features of each method include tolerances, shrinkage, mismatch, surface finish, draft angles, use of cores, porosity, cycle time, cleanliness and physical size. For every product being cast, each method will excel at some of the features and have real problems with others. Part configuration and volumes play a large role in whether the real problems are controlled or left to be constant trouble.

A big cost driver with castings is the use of cores. Cores are used to provide shapes that form internal hollows or undercuts. Figure 2 shows a section of a typical casting that requires a core to form the undercut behind the threaded boss. The undercut was used to save weight. Generally speaking, castings are priced based on weight and casting complexity.

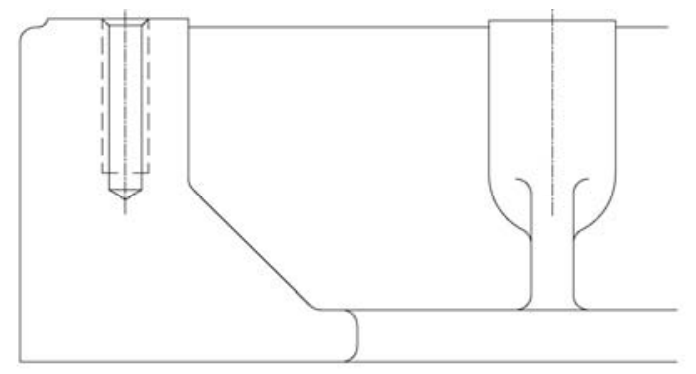

Figure 2. Cored casting

Figure 3 shows the same casting designed to eliminate the core. The cost of a core can be $\$ 1$ to $\$ 2$ based on a final casting cost of $\$ 6$ to $\$ 12$. This is a significant penalty to pay considering 500,000 per year might be manufactured. In the case of the flange, the placement was incidental to the part function but had been placed opposite the boss for a reason that no longer existed. In this case, the designer was so fixed on saving weight that he lost sight of alternatives. As a designer, one must be able to step back and see the whole picture.

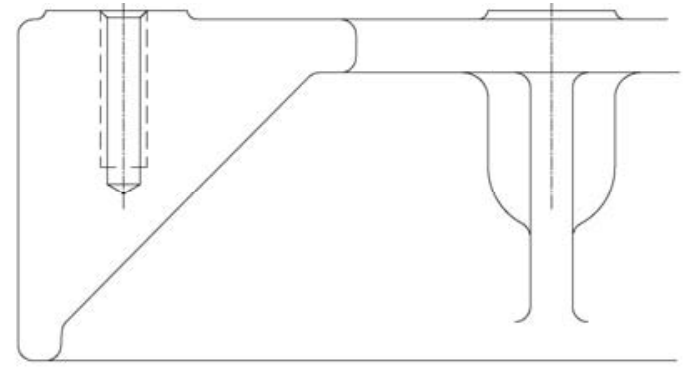

Figure 3. Non-cored casting

During the prototype stage of part development we tend to use smaller foundries that specialize in temporary tooling for low volume production with quick delivery timing. Under these conditions the quality of the castings can be quite high. In fact, the quality can far exceed the ability of the production process to duplicate. Under such controlled conditions the defect rate will be low.

Internal defects are not seen on the surface and may not be exposed by machining. X-ray will show these defects but is not an economical checking method. Confidence must be gained with the casting supplier who will need to have good controls in place to ensure a consistent casting. The low cost foundry can have visually good looking castings but unseen internal defects will lead to failures and high scrap costs. There will be no indication of the possible future porosity issue which gives reduced load carrying ability or the resultant leaking parts when in production. Figure 4 is typical of internal porosity that is not seen even after machining. The porosity in the picture is approximately $10 \mathrm{~mm}$ in size.

Suddenly, the overall low cost foundry is no longer competitive. To change the foundry requires re-validation of the part from the new supplier. Costs for re-validation and timing of several months may lead to the decision not to change the supplier and risk failures in the field and possibly an expensive recall.

The tight tolerances of the prototypes may give the designer too much confidence and lead to reduced clearances that become interferences once the production process levels of distortion or mismatch are reached. 
Prototype tolerances approach $+/-0.7 \mathrm{~mm}$ while production tolerances can be $+/-1.5 \mathrm{~mm}$. By this time production tooling is already in place and will lead to expensive changes to the tools if shape or dimensional changes are made to the design.

When design changes or material changes are made, re-testing may be required. Ultimate strength tests are fast but fatigue testing can take some weeks and in-vehicle testing even longer. Costs increase as the testing takes longer but more importantly the time delays may be prohibitive as the launch misses key dates. If a delay allows a competitor to launch first, the window may have closed on your product.

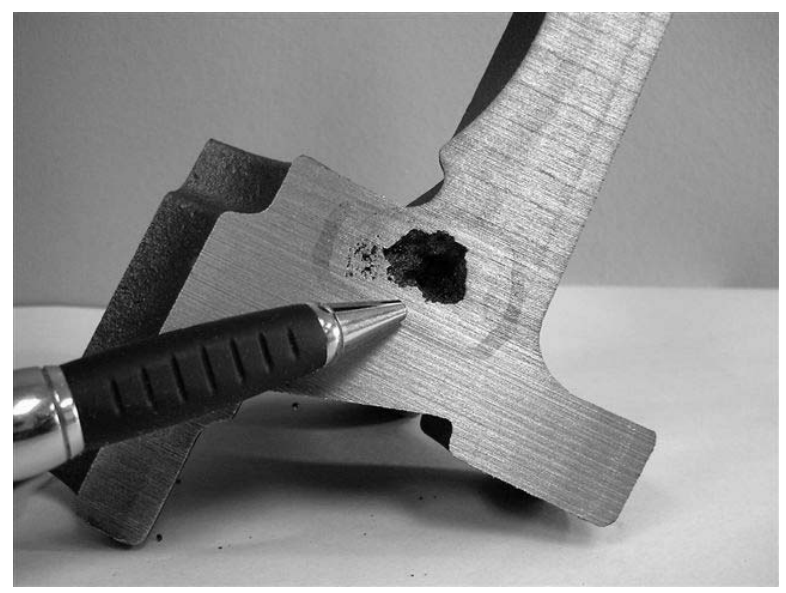

Figure 4. Casting porosity

Forgings can have their own problems, including internal defects, i.e. chevrons, laps and seams, but are much reduced over castings and usually are able to be eliminated. One new shaping method is flow forming, in which parts are approximately $90 \%$ finished, which requires considerably less machining.

Design engineers must understand material selection and ensure the needs of manufacturing are addressed from the very beginning.

\section{Design for manufacturing - Machining}

There are some general design principals of which engineers need to be aware and use day to day that will enhance manufacturability and help to reduce costs. The first principle is to consider how to hold the component during machining. Some parts, by the nature of their design, have natural places on which to sit and be clamped. Other parts require much thought and consideration as to how they will be held. Some shapes will suit one type of machine, i.e. a lathe, while milling operations will show the same part is difficult to hold and needs additions to locate and for clamping.
The part in Figure 5 shows a section of a part that needed the addition of two lugs at one end for clamping and locating purposes. The lugs were designed into existing ribs by adding thickness and size adequate for clamping. They will be a permanent part of the component. The two lugs are somewhat different. The bottom lug is flat on the end which is used as a locator that will help align the casting on the machining fixture. It is called a cast datum. The other lug is only for clamping. Each part requires several alignment datums depending on the fixture design. Normally, there are 3 " $X$ " datums to form a plane, 2 "Y" datums for alignment and one " $Z$ " datum as an end stop.

Cast datums are the link between the casting and the machining. The primary machining datums will be dimensioned from the cast datums to locate the finished machined component "central" within the cast shape. All other machining dimensions and secondary datums are then related back to the primary machining datum.

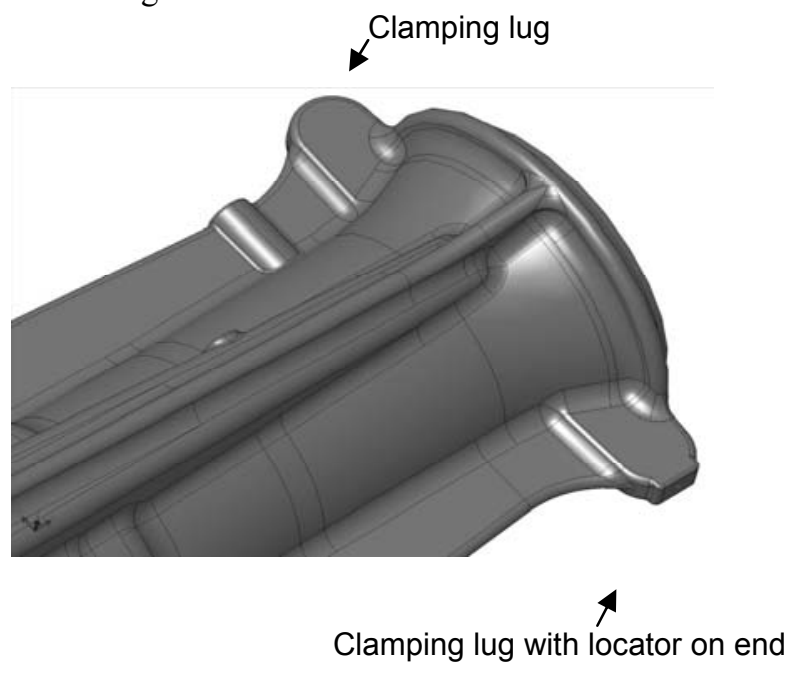

Figure 5. Clamping lugs

Lugs need to be placed and designed so the clamping forces do not distort the part. On some castings the clamping lugs will be removed as a final operation.

\section{Design for machining}

Design engineers are familiar with and understand the analysis tools used for stress, strain, fluid flow, casting solidification, etc., with these tools being readily available and taught widely in engineering schools. The creation of vibration and burrs while machining starts at the design of the part and involves manufacturing tooling and fixturing. Significant research is being done into burr generation and 
elimination and there is a thorough understanding of materials, vibration generation and natural frequencies. Yet, these remain two big problem areas in machining.

Burrs can be reduced by a combination of cutter geometry, speeds, feeds and direction of cut. They can also be reduced by some simple changes to the part. Figure 6 shows one simple change that can be easily incorporated into the raw material design that will effectively reduce burr generation.

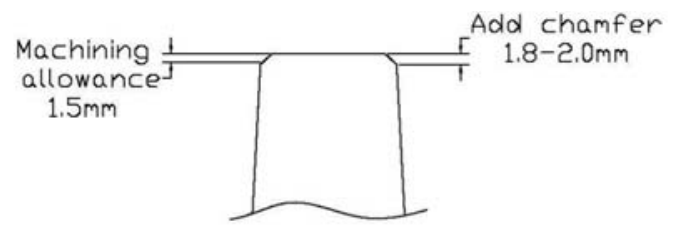

Figure 6. Geometry for burr reduction

Fixturing can play a significant part in the elimination of vibration, called chatter, during machining. Chatter gives rise to large surface finish values, can break cutting edges and it can make it impossible to hold tolerance. The designer must look at the part geometry and review the need to add stiffeners. If the part is not stiff, then it is likely to vibrate during machining. More importantly, is it stiff enough not to distort during operation in the field?

The opportunity to distort, under the load of the cutting forces, is present during machining. This distortion is most evident in the roundness of bearing bores which typically have tight tolerances around $+/-$ $0.013 \mathrm{~mm}$.

Fixturing needs to support a part appropriately and the design needs to have spots on the part where work supports can touch and give rigidity to the set-up.

\section{Design rethink}

The most recent folly that we experienced started as a great idea but ended up being a lesson for everyone involved. Figure 7 shows a bed plate assembly with oil pan and oil pump suction tube and filter.

The bedplate is a complex, semi-permanent mould aluminum casting requiring cores and multiple slides. The cores give the inside shapes and the slides form the weight saving undercuts around the outside. The oil pan can be a die casting but is usually a steel stamping. The pump suction tube and filter are steel.

There is a casting process, called lost foam, that uses pieces of shaped Styrofoam glued together to create the final part. The foam parts are glued to form a tree with a pouring sprue and are dipped in a ceramic coating.

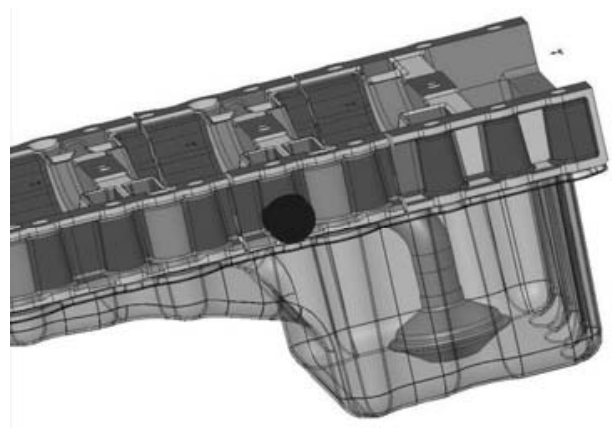

Figure 7. Bedplate assembly

The completed tree is placed in a flask and sand is poured around the tree up to the top of the pouring sprue. When applying vibration, the sand fills any open spaces and in doing so, passages can be formed within the casting. Typical applications for lost foam castings are automotive cylinder heads and blocks. In these cases all the water and some oil passages are formed as part of the process, without the need of complex, expensive cores.

The design engineer on the project decided to reduce the number of pieces in the assembly. Combining the bedplate and oil pan would have made sense if the application could have stood up to the duty and environment. However, it was decided to look at casting the filter into the oil pan.

Casting processes, in general, allow inserts to be placed into the mould and after pouring the metal, the insert is then an integral part of the casting. The filter element, a metal strainer, would have to be placed into the foams during the gluing process. Being cast in place, it would reduce assembly time later.

If the engineer had researched the casting process thoroughly, possibly visited a lost foam foundry and discussed the idea, the method would have been seen as not worthy and no more time would have been wasted. Unfortunately, much design work and analysis was done on the integrated design and it proceeded to prototypes.

The prototype house did a manufacturability review as part of their usual process. It was quite clear there were two major concerns each of which was enough to stop the project. On the first issue it was noted the filter element would prevent the sand from completely filling the filter cavity and passages. The second issue was with the ceramic coating of the foam assembly plugging the filter element. It would need cleaning after casting.

The sand filling and cleaning can always be solved by some special process or assist but the cost of the solutions totally negated any financial or performance savings that should have been realized 
from the lost foam design. The designer's lack of knowledge and understanding of the lost foam process led to several months delay and the costs that were associated with that delay and the additional work.

\section{Dimensions and tolerances (GD\&T)}

After raw material problems, another big cost driver is the way part drawings are dimensioned and toleranced. GD\&T standards [3] change around every 12 years. Companies do not always follow the latest standards and can have their own special standards that supplement the official standard. In some cases, parts of the standard may be replaced. When a drawing is sent out for manufacturing there is great confusion in interpretation of the GD\&T on the drawing.

At a recent series of classes for GD\&T, the instructor started the first class by saying "GD\&T is based on function only". Needless to say the manufacturing engineers in the class were speechless.

The development of the dimensioning of any drawing must be a combination of function and manufacturing with both the raw material (i.e. casting) and finished part drawing coordinated through sensible selection of datums. Datums, dimensions and tolerances must also be measurable by appropriate gauges and /or coordinate measuring machines.

Figure 8 shows a poorly dimensioned set of holes with tolerances that cannot be manufactured and more importantly there is no way to measure the features without introducing so much error that a perfect part could show as unacceptable. Figure 9 shows an alternative dimensional scheme that is able to be manufactured, is measurable and meets the functional requirements.

In figure 8, the original dimensional scheme looks at first glance reasonable. The fact that the two holes are 9.50 inches apart makes it impossible to measure. A shaft passes through both holes and must be located horizontally within the tolerances shown. The datum " $\mathrm{A}$ " hole is assumed to have a perfectly horizontal axis so that when we project it over to the opposite hole we can measure the true position of this hole relative to axis " $A$ ".

If the axis of " $A$ " is not perfectly horizontal but is inclined by 0.001 over the 1.0 " length of the hole, then the projected axis will be 0.009 ', off position when the other hole is measured for true position back to axis "A". This is a real life situation and it happens every day. Unfortunately, the quality inspectors keep rejecting good parts, not because they are bad, but because they cannot measure them with adequate accuracy.

Figure 9, shows a revised dimensional scheme for the same holes where the realities of manufacturing and inspection methods are married successfully with the function of the holes.

Now, the datum is an axis passing through the centre of both holes " $A$ " and " $B$ ". The axis is constructed as a best fit axis when the two holes are probed or the axis can simply pass through the centre of two circles found at the mid point along the length of each hole.

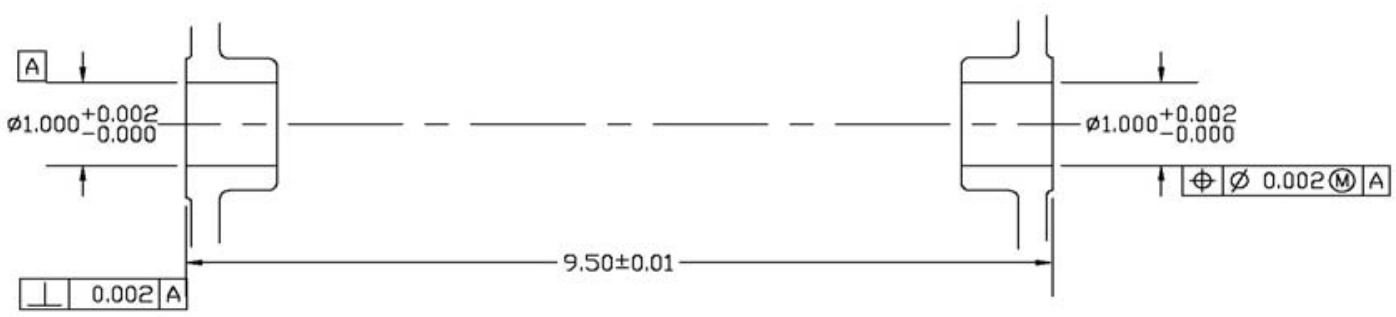

Figure 8. Original dimensional scheme

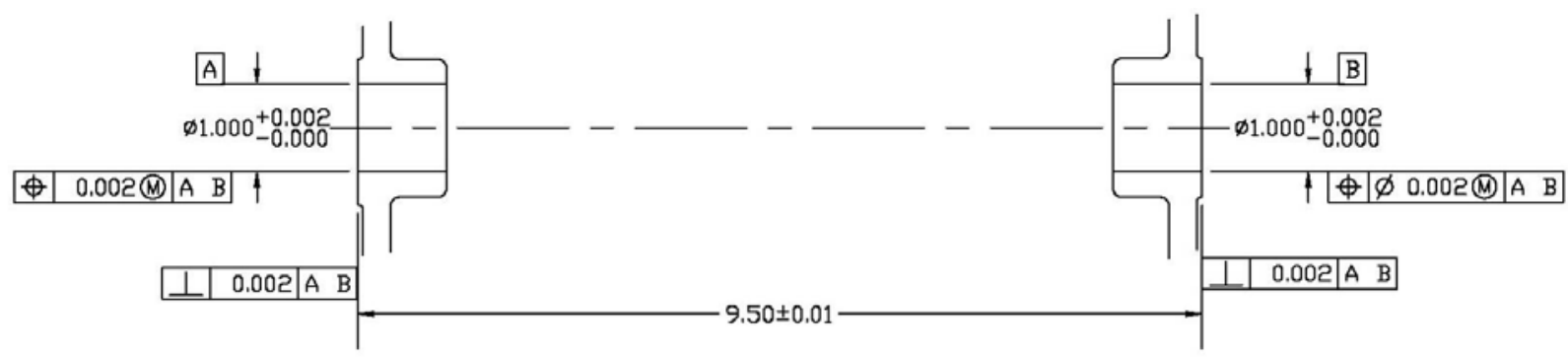

Figure 9. Revised dimensional scheme 
There will be a parallelism or true position call-out of the "A B" axis back to other features.

Under the revised scheme each hole can have up to 0.004 " misalignment at maximum material condition and still be in tolerance and fully functional. The manufacturing process will show excellent capability through the ability to measure the parts.

The following, Figure 10, shows a composite of GD\&T call-outs for similar parts collected from various drawings. In this example " $\mathrm{A}$ " is a face, " $\mathrm{B}$ " and " $\mathrm{C}$ " are bearing journals, " $\mathrm{D}$ " is a cross-hole and " $\mathrm{Y}$ " is a cast datum. One can see they can become very complex when several requirements are stacked together and do require a thorough knowledge of GD\&T for interpretation.

True position, perpendicularity and total run-out are sometimes used interchangeably with designers favoring one more than the other, depending on the application and the dimensional control required.

Obviously, the creation of GD\&T call-outs are another challenge since the designer has to understand all the interactions, make sure there are no conflicts and know how it will be manufactured and inspected. This is a challenge that requires much consultation.
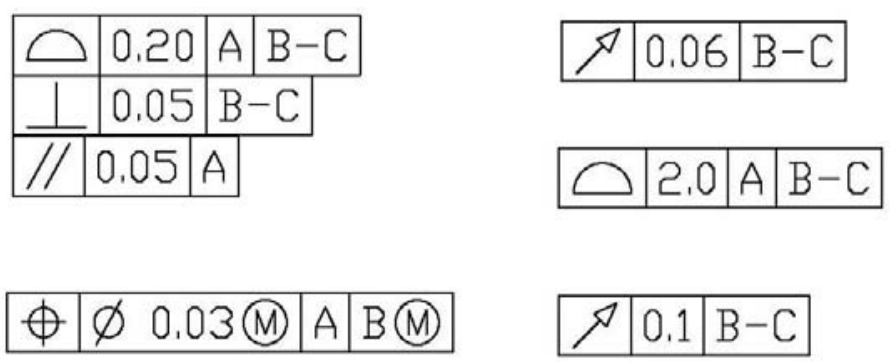

\begin{tabular}{l|l|l|}
$\searrow$ & 0.025 (M) & B-C \\
\hline
\end{tabular}

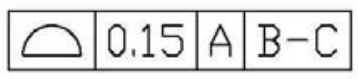

Figure 10. Geometric Dimensions \& Tolerancing examples

\section{Reducing set-ups}

Manufacturing cost is related to the number of part loads each part goes through during its manufacture. Each time a part is required to be loaded and unloaded, possibly on the same machine, a new fixture or on another machine, it causes costs to rise. This gives an opportunity for handling damage and miss-alignment in the fixture that will cause scrap. Therefore, every effort is needed to reduce the number of times a part is loaded. Part design and the type of machine tool being used will determine the number of fixtures and loads required.

Standard machines (CNC) come in 2, 3, 31/2, 4 and 5 axis configurations. Special purpose machines (SPM) are developed specifically for a particular part and can have multiple work stations and axes. Typical examples of SPM's are dial machines and transfer machines. SPM's are suited to high volume manufacturing and once set-up they have almost no flexibility. As the number of axes increase the cost increases but the capability also increases, meaning there will be reduced loadings. Standard CNC machines run $85 \%$ and SPM's $67 \%$ efficiency.
Designers must understand the needs of manufacturing engineers, their machines and tooling and the processing sequence in order to reduce costs overall.

Angles present a real challenge for manufacturing. Most machines are set-up in $\mathrm{x}, \mathrm{y}, \mathrm{z}$, coordinate systems with the axes perpendicular. A forth and fifth axes can be added which gives rotation in these axes. The forth axis comes in 2 versions, indexing ( $1 / 2$ axis) and continuous rotation (4th axis). With indexing the table will rotate, usually, in 1 degree increments and lock in position while the tool is not cutting. Continuous rotation is called contouring and can be synchronized with the rotation of other axes while the tool is cutting. A contouring fourth axis is more expensive and more difficult to program.

The manufacturing preference is for every angular feature to be designed at whole degrees, i.e. 15, 16, 17 etc. or else a contouring machine is required with a 0.001degree resolution. An alternative is to build a fixture that holds the part at an appropriate angle so the feature(s) can be machined at the correct angle. This means another loading is required plus a unique fixture. 
Compound angles are either done on a special fixture or a SPM. Five axis machines are not normally used for high volume parts but are ideal for low volumes such as 20,000 per year. High volume for a SPM is approximately 400,000 per year or higher. Between 20,000 per year and 400,000 per year is $3 \frac{1}{2}$ axis CNC territory.

\section{Consider product growth}

Over time, products go through redesigns which reduce costs, fix quality or performance issues, meet changed regularity requirements or just increase capacity. A typical example of increased capacity is an automotive transmission. Over time engines put out increased torque and power. It is a great sales tool. Unfortunately, every time an engine's output increases all components in the power train need to be able to take the increased loads.

Space is always an issue as designs go for minimum weight and volume. In an automatic transmission space is at a premium. Many components fit inside others and react with them. There are real limits on the diameter and length of the transmission that the components must fit within.

Increasing the torque capacity of the transmission means adding strength to components. If size can't be changed, then the designer needs to consider better materials and better processes that can increase strength. These materials result in higher alloy steels and aluminums. These are more expensive to manufacture and need revised processing that may also increase cost.

Changes to the processes might require a deeper case hardness or changes in types of heat treatment, i.e. carburized or induction hardened. Changes in materials and processing may affect the fatigue life properties, sometimes improving it and sometimes decreasing it. Where life is decreased, shot blasting can be effective in bringing it back to specification. Costs keep increasing with each new requirement.

When material and process changes are not enough, the decision must be made about a redesign of the whole transmission or major subassemblies of it.

\section{Conclusions}

As has been shown in the examples above, there are real issues with the product development process that lead to delays and cost increases. Unfortunately, these issues are common and not the exception.

Industry in North America is under increasing cost pressures as a result of off-shore out-sourcing and the global marketplace. China and India are expanding their industrial base and are fueling much of the cost pressures.

The Japanese automobile companies have demonstrated they can shorten lead times and reduce costs while providing a consistent, quality vehicle and making good profits.

As we look at the examples given here it can be seen that we need to become more efficient in our product development process. Many of the discussed problems could have been avoided by having design engineers spend time in foundries, forging shops, stamping houses and machine shops. With experience in the realities of these industries the design engineer will gain the knowledge of what to expect of a given material or process.

Technical schools and universities also need to consider these issues when they prepare course curriculum. Employers should consider hiring people with a strong background in these areas or be prepared to invest in the time and effort to ensure the employee obtains the appropriate experience as part of the training and development.

Strong education coupled with appropriate materials and manufacturing experience is a necessary part of the training for the next designers if we are not to let our industrial base disappear. When we have a designer with the education and experience together with creativity and common sense, we have a powerful solution.

\section{Acknowledgements}

The author wishes to acknowledge the support of Dr. S. Lambert, University of Waterloo, in the preparation of this paper and the many design engineers who have unwittingly provided the material on which this paper is based.

\section{References}

[1] International Standards Organization, ISO 9000:2002 Management System, ISO/TS 16949:2002 Technical Specification Quality Management Systems, www.iso.org

[2] Automotive Industry Action Group, Quality System Manuals, www.aiag.org

[3] American Society of Mechanical Engineers, ASME Y14.5M-1994 Dimensioning and Tolerancing, www.asme.org 